\title{
User's Need in Architectural Spaces Development, Existing Kitchen Design in Northern Cyprus
}

\author{
By Rasha Moree Tarboush ${ }^{1}$, Çilen Erçin ${ }^{2 *}$
}

\begin{abstract}
This paper examines the kitchens' evolution throughout history and the increasing interest of architects in the kitchen space to meet user needs. The method of studying this paper is part of a research project that reviews a series of changes in the architecture of kitchen spaces in the past 100 years, with a focus on the types of kitchen that have been used and how to develop them over time according to the dimensions of the space and the needs of the user. This paper shows the importance of user needs in architectural kitchen design development. The study focuses on modern kitchens and their types according to the available kitchen dimensions. The case study is centered on how the user needs to influence the design of an existing kitchen, Northern Cyprus.
\end{abstract}

Keywords: User's Needs, Architectural Space, Kitchen Space, Kitchen Design, Modern Kitchen

\section{Introduction}

User needs express people's values, aspirations, and goals, so the designer has to understand the people's needs to be able to design a product that helps meet the user's needs. Delving into the user's personality, studying his past experiences, studying the different types of users who will use the product or design, and imagining the characters will help the designer understand the user's needs, experiences, behaviors, and goals to seek their fulfillment, (Wilson, 2006).

Architectural space expresses the area where the movement takes place, as it is not possible to create a space without form. Space expresses something invisible and intangible to design in terms of shape, colors, and materials. Space can be a negative or positive space, deep or shallow, closed or opened, two or three dimensions, (Pellegrino and Jeanneret, 2009).

The kitchen space is a part, space, or room of the house that is used to prepare food, and part of it can be used as a dining area, as it depends on the kitchen area, as well as the kitchen area can be part of a room, (Bech-Danielsen, 2012). In primitive societies, people used to build their homes by themselves using a model that was proven by experience to being economical, comfortable, and durable for a certain period.

However, the user needs leading to the development of kitchen design over time and the increased interest of architects in it, (Sani et al., 2011). This paper examines the kitchens' evolution throughout history and the growing interest by architects in designing kitchens to meet user needs. This paper aims to show the user needs' importance in architectural design, especially in kitchens, as the study focuses on modern kitchens and studies their 
types' development according to the dimensions of the place and the needs of the user. This study provides information that benefits architecture students and architects in designing kitchens and how to choose the proper type according to the areas, dimensions, and user needs. Understanding user needs and being able to meet them is one of the most important design stages that lead to design success.

This study provides information about the architectural void, and importance of user needs' understanding during the design period, and the effect of the user's needs on the space, as meeting the user's needs leads to the success of the design. This research focuses on the kitchens' design and their types, as the kitchen spaces' design has evolved according to the needs of the user, the spaces, and the impact of the user's needs on them.

This paper aims to show the user needs' importance in architectural design, especially in kitchens, as the study focuses on modern kitchens and their types which developed according to the dimensions of the place and the needs of the user. The case study centered on how user needs to influence the design of an existing kitchen, Northern Cyprus.

\section{Methodology}

The method of studying this paper is part of a research project that reviews a series of changes in the architecture of kitchen spaces in the past 100 years, with a focus on the types of kitchen that have been used and how to develop them over time according to the dimensions of the space and the needs of the user. The study focused on architecture and design change, as the difference in design depends on the different conditions and needs of each time. The study will show how kitchen design has changed and how this change relates to daily life over time. It turns out that architecture has changed radically from 100 years until now, through the thinking development about the good housing concept and the provision of comfortable spaces that meet the needs of the constantly increasing user according to the developments of the time. All information, examples, and plans were taken from multiple articles and websites, as well as different types of kitchens according to spaces were included and proposals were made for each type explaining the multiplicity of design methods according to the needs of the user. In the end, work was done on a design that is present on the ground in Cyprus, and after asking some questions to the residents of the house and knowing their needs in the kitchen and the negatives and positives of the current design, then two designs have been suggested to meet users' needs.

\section{Architectural Spaces}

Space is the inner and outer parts that seem with a certain form, as voids are the spaces through which we move. Form is a block made up of materials group that give a building its shape. Architecture is the art of designing and building spaces to give a habitable place while providing for the needs of the user, (Your Own Architect, 2020). As shown in Figure 1, to create useful architectural spaces, first of all, we need to work on the site analysis like thinking of:

- The site context: such as space requirements, relationships, processes, objective, maintenance, environment, equipment, and access.

- User's needs: such as site, zoning, climate, geological factors, adjacent buildings, traffic 
conditions, and topography.

- Form: such as structure, circulation, zoning, energy, image, climate control, construction process, and construction types.

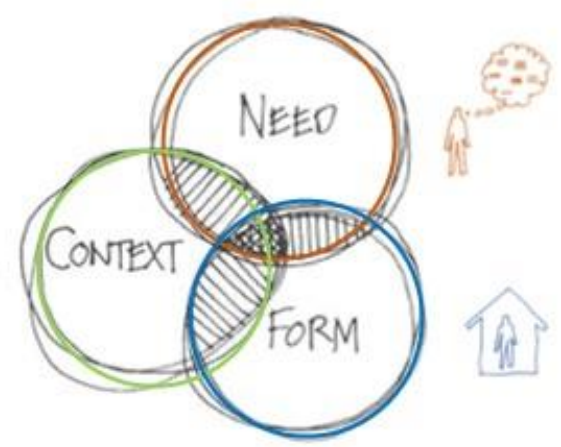

Figure 1: Site analysis, edited by the author, 2020 (Slide Share, 2017).

The second stage is the design process and starting to put the first lines of the design, (Slide Share, 2017). Architecture acquires its characteristics from space, where the architectural space is divided into two parts: closed space and open space. An enclosed space is a space surrounded by a structure with few openings, such as windows, doors, skylights, or a patio, while open space is a space with a large opening, few walls, or other barriers, (Figure 2).

Figure 2: Closed and open spaces, (By author, 2020).

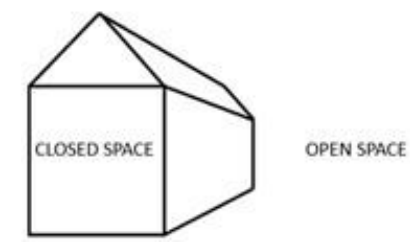

Sometimes the closed space can be used as open space at the same time, and this is achieved when the closed space has a movable wall from one or more sides, so we can use the space as an open or closed space, (Figure 3).

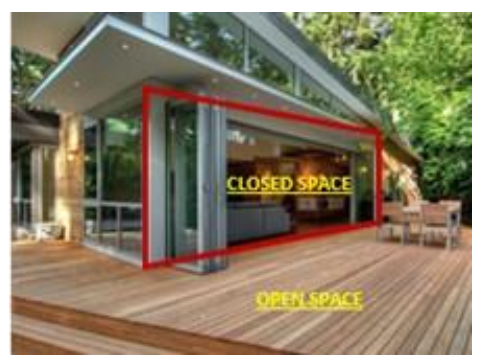

Figure 3: Using the spaces as an open and closed at the same time, edited by the author, 2020 (Medialize, 2020).

3.1 User's Needs Effect on Architectural Spaces: 
Personality As shown in Figure 4, user's needs include private, social, organizational, public, and cultural areas. So all of these areas affect the architectural design, where the designers have to think of and understand all of these points before starting their design process to can create good and useful spaces for users, while all of the points of needs change from one place to another, (Science in the classroom, 2020).

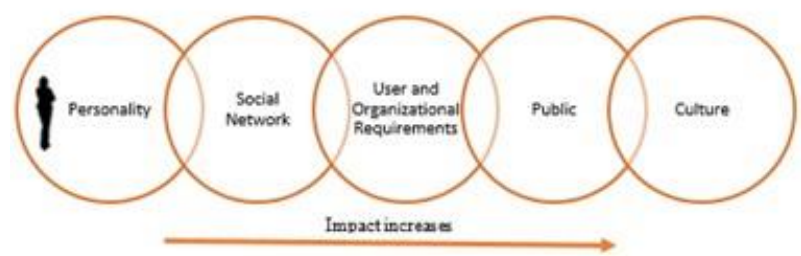

Figure 4: Areas of User's needs that affect architectural designs, edited by the author, 2020 (Science in the classroom, 2020).

\subsubsection{Spaces Design Principles}

The "usability of a space" depends on the extent to which this space meets the needs of the user. Architectural spaces express the possibility of people entering and exiting and performing daily activities. The work environment and the design of spaces in architecture arise through understanding the biological, psychological, and social aspects of the user to be able to create suitable and comfortable spaces for him. Therefore, it is important when designing spaces to identify the specific needs of the user and not to design for unknown persons. As shown in Figure 5, design principles are the basic elements and ideas that achieve a successful design, where the applying of design principles helps to create useful designs for users. as the elements include the following: line, shape, orientation, size, texture, and color, (Thoring et al., 2018).

LINE
SHAPE
SPACE
TEXTURE
COLOR

Figure 5: The basic elements of design, (By author, 2020).

\subsection{A Kitchen Design Timeline: 100 Years of Kitchen Evaluation}


Kitchen spaces' design has evolved depending on the users' needs. Before the 1940s, the kitchen spaces were very small and the functions were used separately, then they combined the functions to be as one block. In the 1920s, the new architecture reevaluated the homes' construction, the spaces' design, and defining the aesthetics that depend on the functional criteria.

At that period, L-shaped kitchen had a sideboard placed along the wall and a storage center with a sink, (Figure 6), (Baden-Powell, 2006).

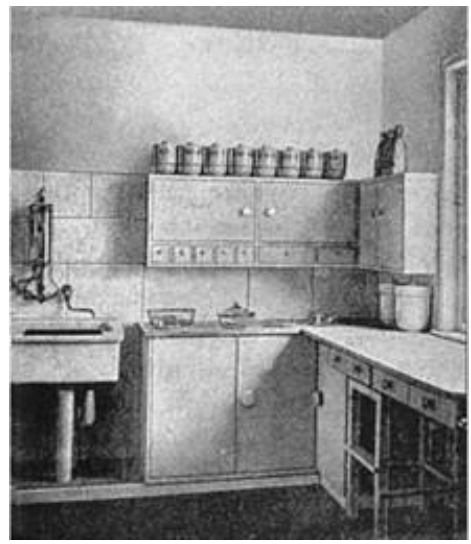

Figure 6: Das Haus am Horn kitchen (Baden-Powell, 2006).

During the 1920s and 1930s of the last century, the kitchen continued its role as a small space for preparing food and arranging all equipment in a manner appropriate to space as much as possible, but the application of the methods presented by culinary scientists led to raising the level of cooking and the introduction of new equipment and appliances for the kitchen, which led to a rethink in the development and Changing the design of the kitchens to suit the needs of the user as well as comfortable of moving, (Figure 7), (Plante, 1995).

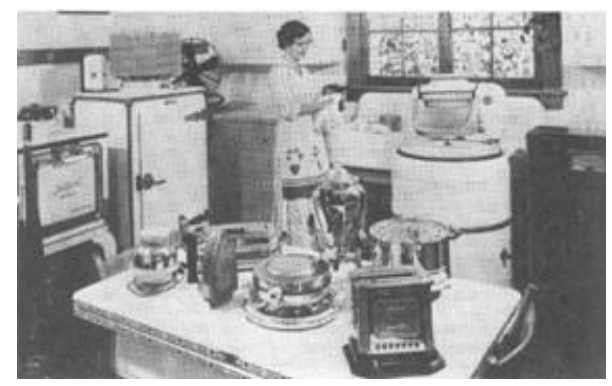

Figure 7: Kitchens design between the 1920s - 1930s, (Plante, 1995).

Kitchens before the 1940s, like the American kitchen which meant a lot of wood, where cabinets, floors, and countertops were wood, (Figure 8), (House Beautiful, 2016). During the 1940's, kitchens had a gas stove with hotplates, a refrigerator, prefabricated cabinets, a stainless steel sink, and hardtops (Plante, 1995). In the 1940s there began to be an increase 
in interest in kitchens, and in thinking about user comfort. And in the1950s, the designs seemed to be more luxurious in terms of design and materials used, where steel material became the usual material for designing cabinets, as well as, the linoleum was used for the floor, (Figure 9), (Apartment Therapy, 2017).
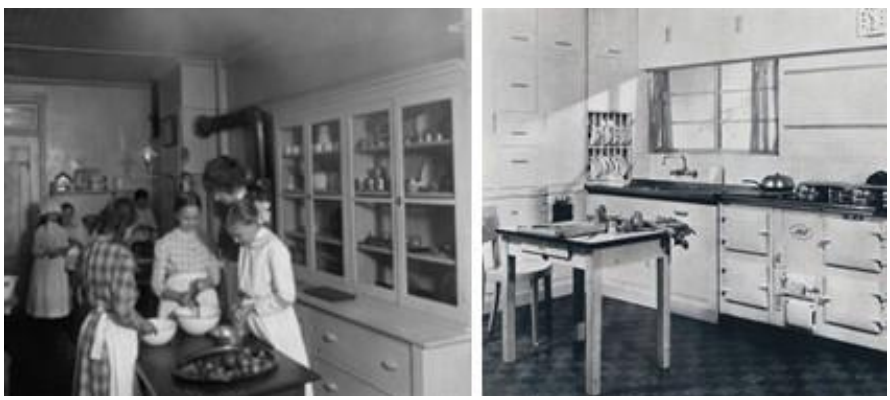

Figure 8: Kitchens before the 1940s, (Apartment Therapy, 2017).
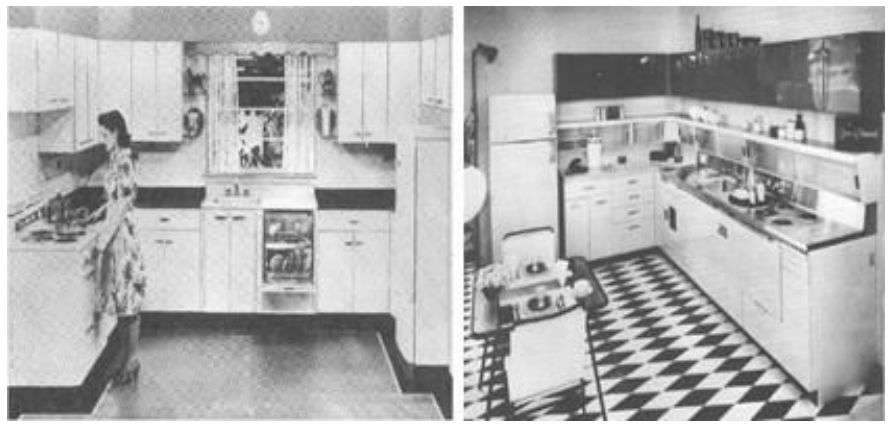

Figure 9: Kitchens in the 1950s, (Plante,1995).

In the 1960s-1970s, kitchens were becoming larger, with an abundance of working space. Instead of steel, the dominant material used was wood, especially pine cupboards. The floor material was linoleum made with vinyl, (Figure 10). During this period the kitchen appliances were advancing very quickly, as kitchens became designed for entertainment. And the options, colors, and patterns also increased, (The Spruce, 2020).
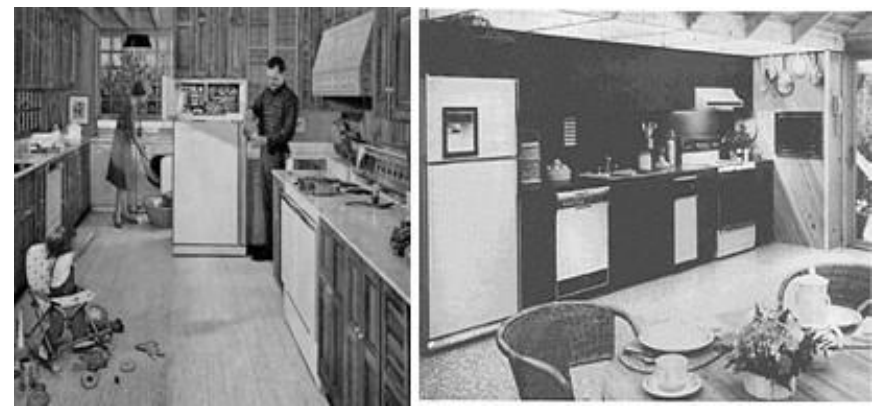

Figure 10: Kitchens in the 1960s-1970s, (The Spruce, 2020).

In the 1980s-1990s, they used oak cabinets, and linoleum flooring, (Figure 11). The 1980s 
- 90s kitchens' bones are similar to today's kitchen designs, as it's the fixtures and color schemes that have changed the most, (Kaster, 1996).
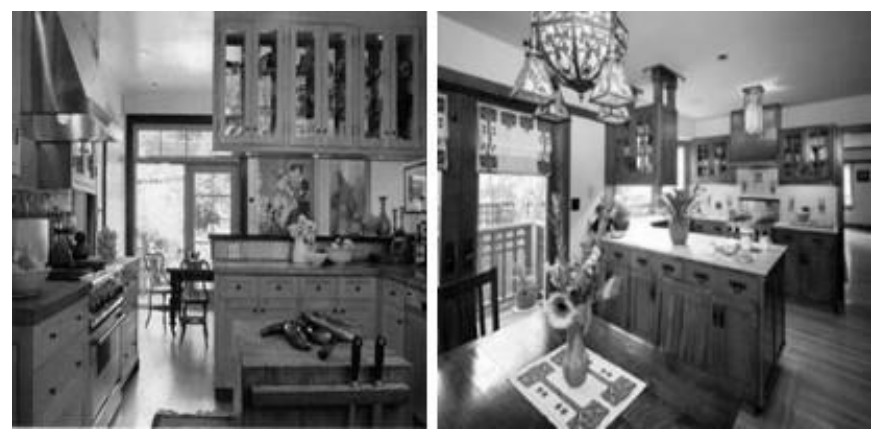

Figure 11: Kitchens in the 1980s-1990s, (Kaster, 1996).

In the 21 st Century, modern kitchens include glass, concrete, wood, stainless steel, quartz, or soapstone materials, and materials used for flooring are reclaimed or engineered wood, bamboo, cork, or traditional linoleum tiles, (Figure 12). In contemporary kitchens, the kitchen did not differ much in terms of planning, design, size, and storage, but the production of kitchen appliances increased with many and multiple functions, as it differs from its predecessor and provides great luxury to the user, (Freeman, 2004).
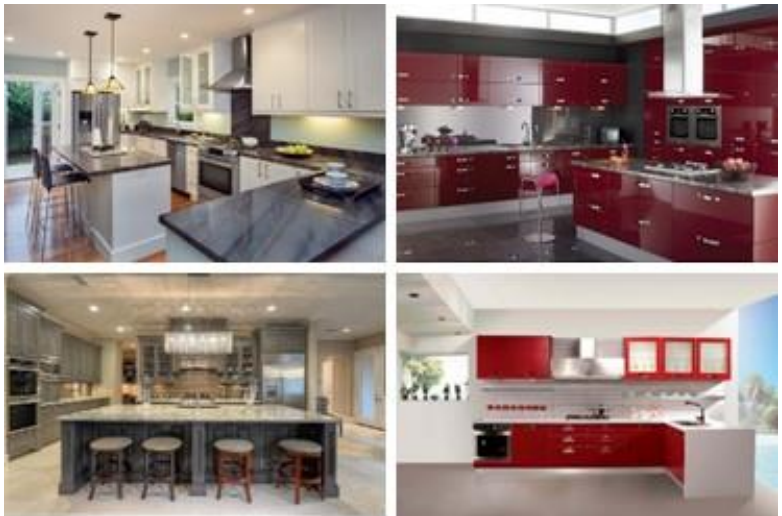

Figure 12: Modern kitchens in the 21'st century, (Grundig, 2019).

\section{Kitchen Design and Layouts}

The modern designs appeared around World War I and featured flat surfaces, geometric forms, and little or no ornamentation or adornments. Modern kitchens are broadly categorized as less traditional and more contemporary. All modern design has specific roots in terms of its time period, style, and inspiration. Modern kitchen designs ensure that the creative and cultural norms are pushed and are ever-growing. Below are the signature characteristics of a modern kitchen design, (HGTV, 2020).

- Space and lighting. 
- Modern Kitchen Doors.

- Modern Kitchen Layouts.

- Kitchen Cabinets and Benchtops.

Effective kitchen design includes layout processes, appliances, surfaces, and design details to create an easy cooking space to use and fun to cook, involves increasing the functionality, space, and defining the home owners' individuality, (Grundig, 2019). Designing a new kitchen requires determining the users' needs, so before starting the design should ask the users the following questions:

- Where do user need the most worktop space? Next to the stove and oven, or closer to your serving area?

- What are the user storage needs?

- Does user have kids?

- Where do user want to store the appliances and utensils that use most?

- Does user want the tools stored away or out for quick use?

- Does user require a double-door fridge or gas stove?

All of these decisions will affect the designer layout. So giving some thought about how users use the current kitchen will help designers plan a new useful one. It's the safest way to ensure that users' daily needs are not overlooked. There are many things that kitchen users do not want to give up and that need sufficient and comfortable spaces and places, so the designer must strive to fulfill the user's need by using the spaces fully and correctly to try to meet all requirements while providing comfortable movement, (Wonderful Kitchens, 2015).

\subsection{Types of Modern Kitchen Design:}

Getting a kitchen layout right consider as the most important factor in ensuring a practical and functional kitchen area, whether the kitchen is cramped and small or expansive and large. A clever layout helps designers to get the most out of the spaces. Especially in the kitchen design, there is a lot more to layout than just placing the furniture and cabinetries, such as:

- Ergonomics: has a huge role.

- Getting the heights right.

- Ensuring enough space for comfortable movement.

- Placement of appliances.

- Ease of use.

All these factors effect on user enjoyment of the kitchen space, (Grundig, 2019).

\subsubsection{The 6 Most Popular Kitchen Layout Types}

Kitchen design is very important to work, and the engineer has to look at the smallest details that can design an integrated kitchen in terms of functionality and aesthetics, and choosing the type of kitchen is one of the most important design stages. The 6 most popular types of kitchens will be explained in this part. The types are:

- Single wall kitchen (One wall kitchen).

- Galley kitchen.

- L-shaped kitchen. 
- U-shaped kitchen.

- Island kitchen.

- G-shaped kitchen (Peninsula kitchen).

\section{- The Single Wall Kitchen (One Wall Kitchen)}

The single wall kitchen (one wall kitchen) is a kitchen that is built into one linear wall, where a one-wall kitchen has all cabinets, appliances, and countertops on one wall. The one wall kitchen should be a minimum of $2.4 \mathrm{~m}$ long, (Figure 13), (The Spruce, 2019).

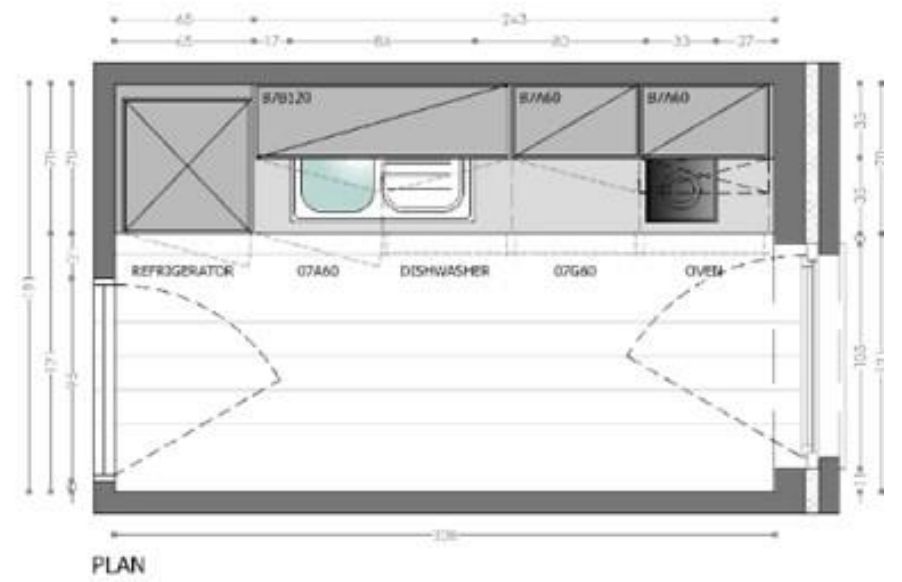

Figure 13: The single-wall kitchen plan, (The Spruce, 2019).

As shown in Figure 13, the kitchen design has no window because of using the upper cabinets. In this type of kitchens, it's better to do not the upper cabinets, due to the necessity of having a window. In Figure 14, the author advises the designers to use the single wall kitchen with one window, two doors, and with dimensions 3 x $1.5 \mathrm{~m}$, where the design can include just one door; it's up to on the other adjacent spaces, as well as the single wall can have a window with upper cabinets on the window's sides where it's up to user's needs.

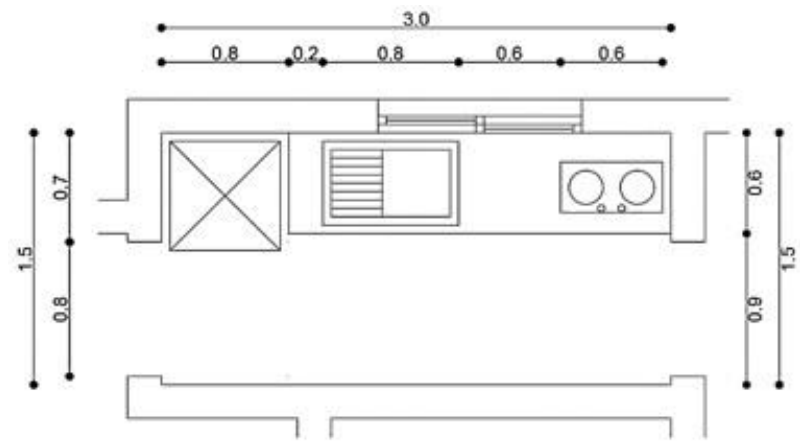

Figure 14: The single-wall kitchen plan with standard dimensions, by using the AutoCAD program, By author, 2020).

Table 1: The needs advised for single-wall kitchen design plan, (By author, 2020). 


\begin{tabular}{|c|c|c|c|c|}
\hline Type & Wall & Window & Door & Dimension \\
\hline Single Wall & 1 & 1 & 1 or 2 & $3 \times 1.5 \mathrm{~m}$ \\
\hline
\end{tabular}

\section{- The Galley Kitchen}

As shown in Figure 15, the galley kitchen is a long and narrow kitchen that has base cabinets, counters, wall cabinets, or other services located on one or both sides of the central walkway. It commonly has a width that varies between 1.2-1.8 $\mathrm{m}$ with a linear length of 2.1-3.8 m, (Build, 2020).

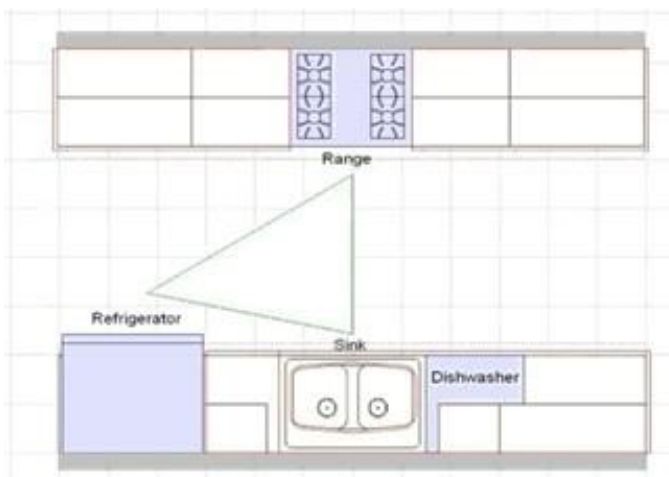

Figure 15: The galley kitchen plan, (Build, 2020).

In this type, it's not correct to design a window for both walls, this is because the user needs a wall with lower and upper cabinets.

In Figure 16, the author advises designers to be careful of good use of spaces by having two walls for cabinets, two windows, two doors, and with dimensions $4 \times 2 \mathrm{~m}$, where one the walls will have lower cabinets with windows and the other one will have lower and upper cabinets, and in this type also, it can be used 1 door or 2 doors that depending on the neighbor spaces, as well as on the user needs.

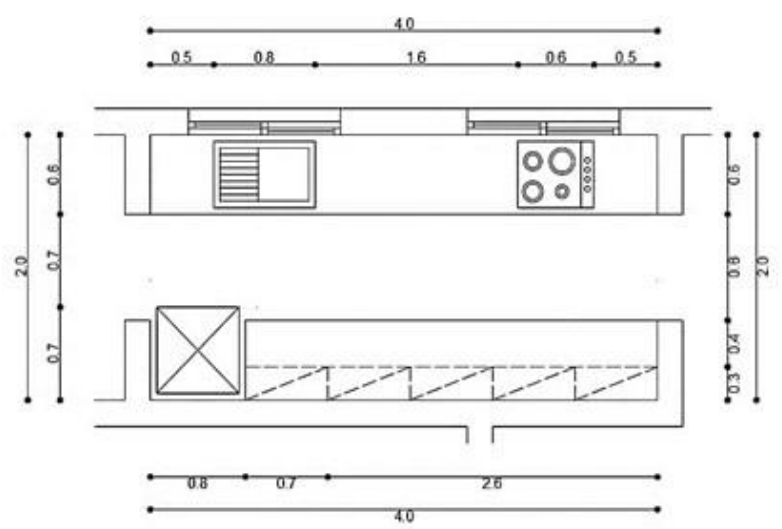

Figure 16: The galley kitchen plan with standard dimensions, by using the AutoCAD program, (By author, 2020).

Table 2: The needs advised for galley kitchen design plan, (By author, 2020). 


\begin{tabular}{|c|c|c|c|c|}
\hline Type & Wall & Window & Door & Dimension \\
\hline Galley Kitchen & 2 & 2 & 1 or 2 & $2 \times 4 \mathrm{~m}$ \\
\hline
\end{tabular}

\section{- The L-shape Kitchen:}

As shown in Figure 17, the L-shaped kitchen is one of the most efficient kitchen layouts for the modern home is L-shaped kitchen. L-shaped kitchens offer an easy and efficient workspace and allow appliances and cabinets to be installed along right angled walls with an open area in the center. L-layout can fit perfectly into a $3 \times 3 \mathrm{~m}$ kitchen, which is still considered the benchmark for estimating the costs of cabinets and countertops, (Kaboodle, 2020).

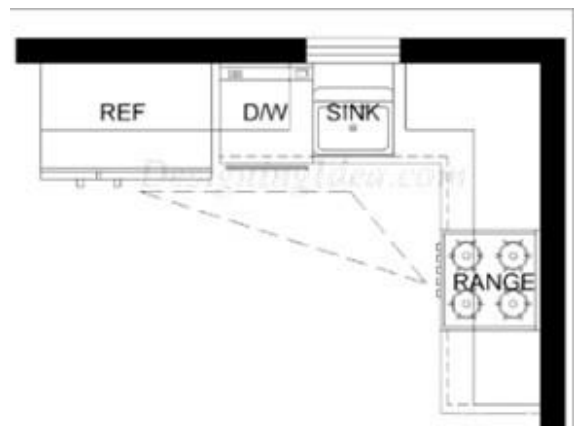

Figure 17: The L-shape kitchen plan, (Pinterest, 2020).

The example in Figure 17, has no details about the dimensions and openings. As shown in Figure 17, the author advises designing the L-shape kitchen with two walls for cabinets, so here the window can be located in one wall and the second wall will have lower and upper cabinets, as well as, it can include an extra window on the third wall. In Figure 18, advised using two walls, two windows, and one door with standard dimensions $3 \times 3 \mathrm{~m}$.

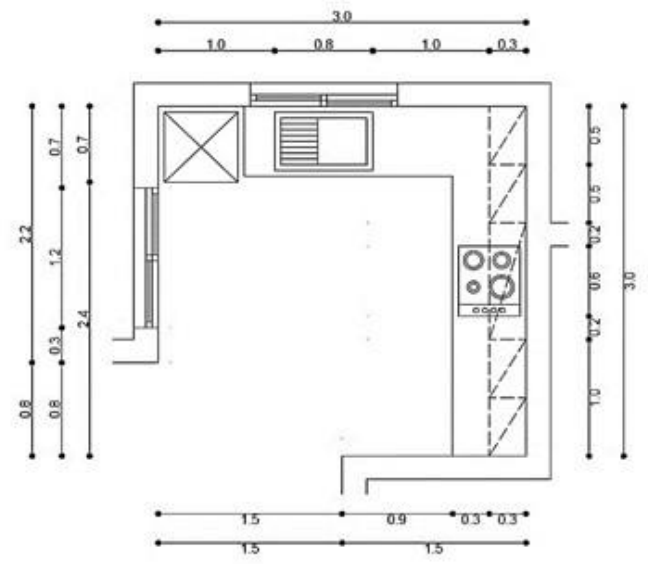

Figure 18: The L-shape kitchen plan with standard dimensions, by using the AutoCAD program, (By author, 2020). 
Table 3: The needs advised for L-shape kitchen design plan, (By author, 2020).

\begin{tabular}{|c|c|c|c|c|}
\hline Type & Wall & Window & Door & Dimension \\
\hline L-shape Kitchen & 2 & 2 & 1 or 2 & $2 \times 4 \mathrm{~m}$ \\
\hline
\end{tabular}

\section{- The U-shape Kitchen:}

As shown in Figure 19, the U-shaped kitchen units place on the three sides with the top of the ' $\mathrm{U}$ ' left open for a doorway or an open plan living room. It can be combined with dining areas or even a kitchen island if the width of the room allows. U-Shaped Kitchens have widths ranges between 2.7-3.7 $\mathrm{m}$ and depths varies as desired, (Home Designing, 2020).

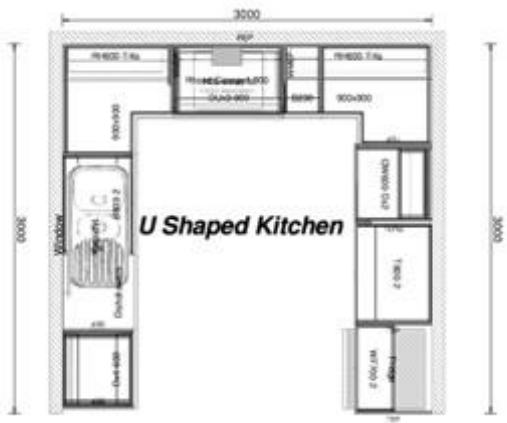

Figure 19: The U-shape kitchen plan, (Home Designing, 2020).

The example in Figure 19, has no details about the dimensions and openings. For this type of kitchen, the author advises containing one wall with window and two walls with lower and upper cabinets, or two walls with windows and the third one with lower and upper cabinets. This is up to the user's needs and opinion. In Figure 20, advised using three walls, two windows, one door, and with dimensions 4 × $3 \mathrm{~m}$.

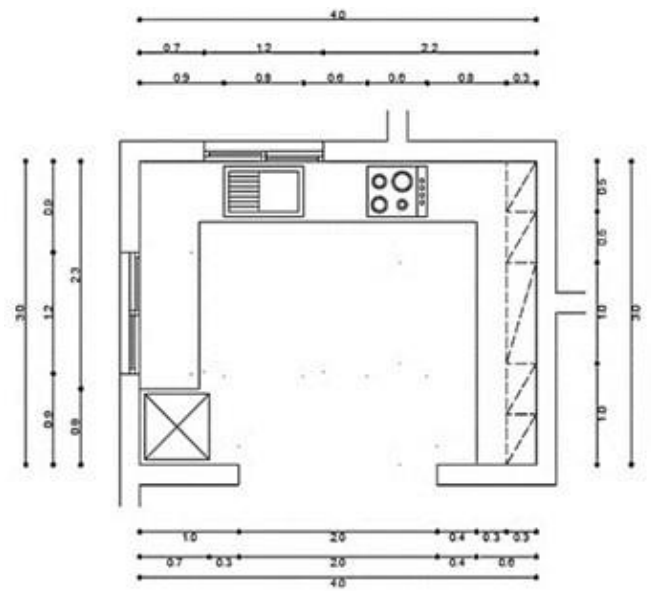

Figure 20: The U-shape kitchen plan with standard dimensions, by using the AutoCAD program, (By author, 2020). 
Table 4: The needs advised for U-shape kitchen design plan, (By author, 2020).

\begin{tabular}{|c|c|c|c|c|}
\hline Type & Wall & Window & Door & Dimension \\
\hline G-shape Kitchen & 3 & 2 & 1 & $4 \times 3 \mathrm{~m}$ \\
\hline
\end{tabular}

\section{- The Island Kitchen:}

As shown in Fuger 21, the island kitchen is a freestanding piece of cabinetry placed in a kitchen to supplement the countertop space. It is equally common to elevated stools along as a supplemental dining area. The Island Kitchens at least $2.4 \mathrm{~m}$ deep and more than 3.6 $\mathrm{m}$ long, while the island can vary in shape and size, but the minimum recommended size of a fixed island is about $1 \times 1 \mathrm{~m}$, (The Free Dictionary, 2020).

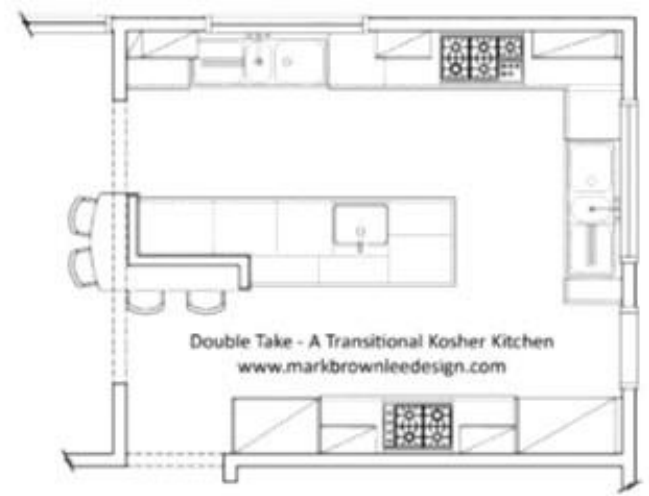

Figure 21: The Island kitchen plan, (HGTV, 2020).

The same as U-shape with island. The island can be a table, workplace, or both of them, this up to area and needs. In Figure 22, the author advises using three walls, two windows, one door, and with dimensions 4 × $3 \mathrm{~m}$.

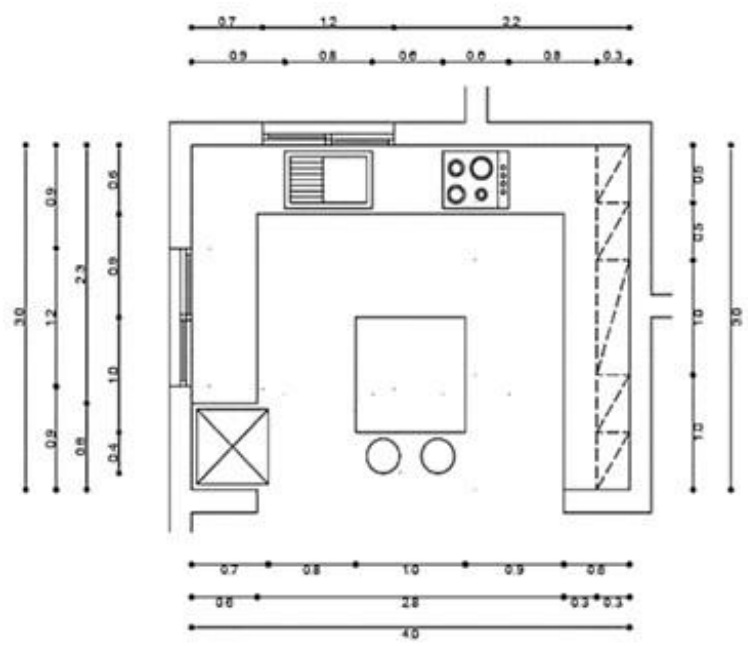

Figure 22: The island kitchen plan with standard dimensions, by using the AutoCAD program, (By author, 2020). 
Table 5: The needs advised for island kitchen design plan, (By author, 2020).

\begin{tabular}{|c|c|c|c|c|}
\hline Type & Wall & Window & Door & Dimension \\
\hline Island Kitchen & 3 & 2 & 1 & $4 \times 3 \mathrm{~m}$ \\
\hline
\end{tabular}

\section{- The G-shaped Kitchen (Peninsula Kitchen)}

As shown in Figure 23, the G-shaped kitchen (Peninsula kitchen) is similar to an island in that it's a unit with a worktop, but instead of standing free in the middle of your kitchen, one end is attached to the wall.

The G-shaped kitchens have an overall width that ranges from 3-4 $\mathrm{m}$ with a depth from 3.7-4.6 m, (Wren Kitchens, 2020).

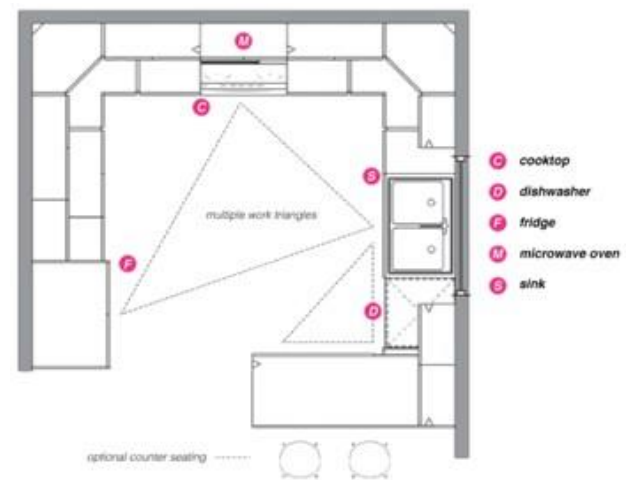

Figure 23: The G-shaped kitchen plan, (Pinterest, 2020)

This type of kitchens combines both U-shape and island in one kitchen, but the island connected to the wall. . In Figure 24, the author advises using three and a half walls, three windows, one door, and with dimensions $5 \times 4 \mathrm{~m}$.

The example in Figure 23 and the author suggest are good examples, where the use of windows or upper cabinets is up to the user's needs.

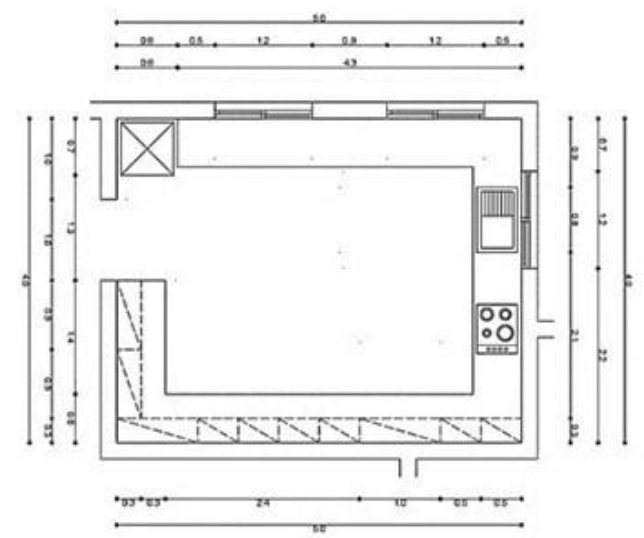

Figure 24: The G-shaped kitchen plan with standard dimensions, by using the AutoCAD program, By author, 2020). 
Table 6: The needs advised for G-shaped kitchen design plan, (By author, 2020).

\begin{tabular}{|c|c|c|c|c|}
\hline Type & Wall & Window & Door & Dimension \\
\hline G-shape Kitchen & 3.5 & 3 & 1 & $5 \times 4 \mathrm{~m}$ \\
\hline
\end{tabular}

\section{User's Needs Effect on an Existing Kitchen Design}

The design of spaces varies according to the needs of the users, as in many cases changes are made in the design of existing spaces as a result of the user's change or the evolution of the user's thinking and needs. The same applies to the design of kitchen spaces. The utilization of space is considered a very important matter in the design of the space and its importance increases due to the increase in the need for larger storage spaces while maintaining an adequate and comfortable working space, as well as for movement space.

\subsection{One Existing Kitchen Design in Northern Cyprus}

A kitchen located in one of the North Cyprus homes has been chosen, as users face a problem in the designer not utilizing spaces well during the current design and not having enough storage space. The place was visited, some pictures of the kitchen were taken, and some questions were asked to the users to can understand their needs and take them into consideration in suggestion a new design for the kitchen, (Figure 25).
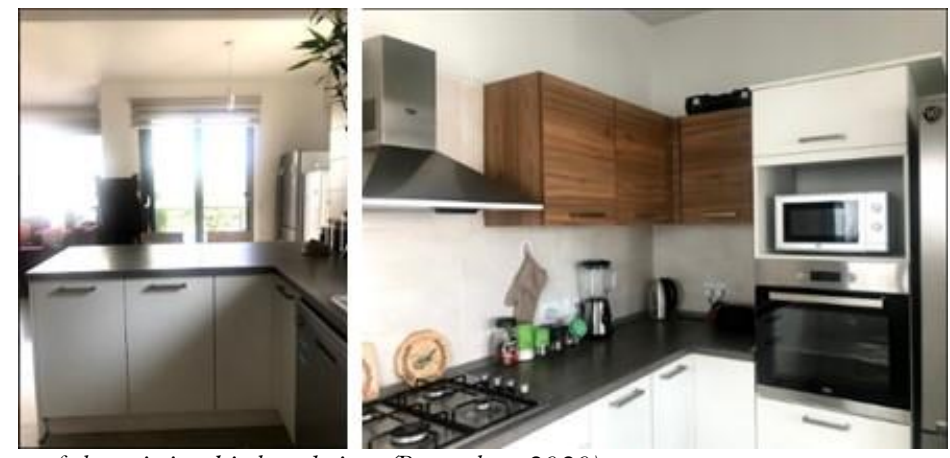

Figure 25: Photos of the existing kitchen design, (By author, 2020).

Some main questions for users:

- What are the problems in the exiting design?

- How are they thinking to solve the problems?

- Do they want it to be as an opened kitchen to the salon or closed?

- Do they have a kids?

- Do they have disabled people living with them?

- Where do they need the most worktop space?

- How many storages they need?

- What are the storage types they need?

- Where do they want to store the appliances and utensils that use most?

- Do they want the tools stored away or out for quick use? 
- Do they require a double-door fridge or gas stove?

After getting the answers and depending on the users' requests and needs, two designs for the kitchen by using two different kitchen design types for each one has been suggested.

\subsection{Suggestions for the Existing Kitchen Design Depending on User's Needs}

The existing kitchen type is a G-shaped kitchen. The kitchen space is opened to the dining and salon space. The kitchen has $3.40 \mathrm{~m}$ in length and $3.13 \mathrm{~m}$ in width, having one window, one opened entrance. The kitchen designed with lower and upper cabinets, as the upper cabinets have used just on parts of two walls of the kitchen, and the cabinets are not connected to the roof, where having $35 \mathrm{~cm}$ between the cabinet and the roof, (Figure 26). The designer did not make good use of the space in this kitchen design, so easily can expect that the designer did not fully consider the needs of the user, but rather that his design was purely economic intended to serve the company only.
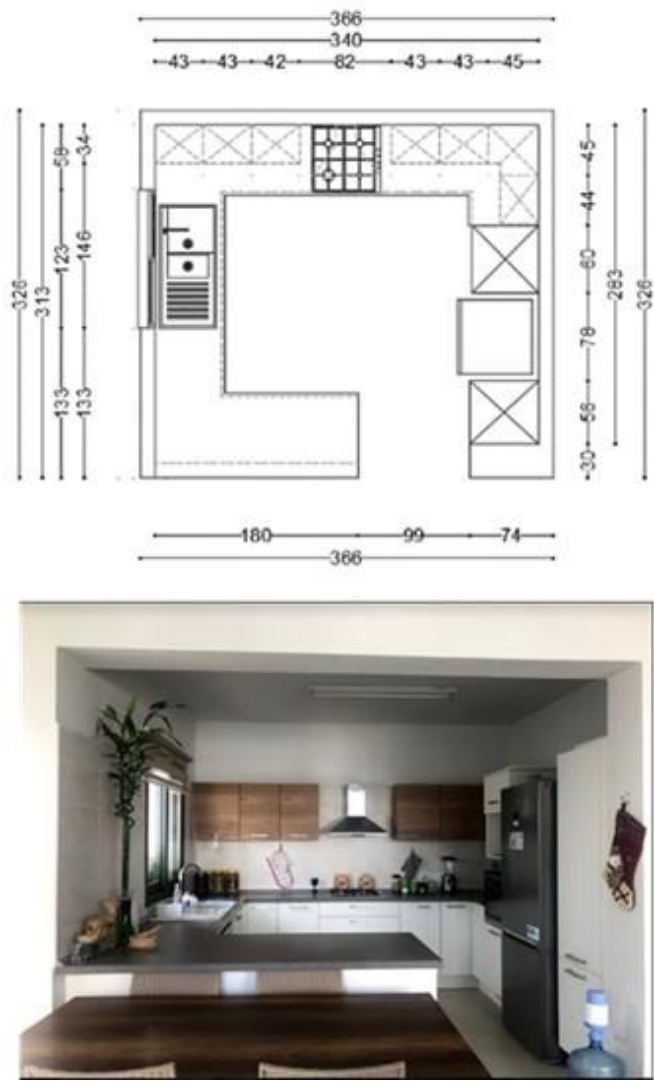

Figure 26: The existing kitchen design, (By author, 2020)

For this kitchen two designs have been suggested, where both of them have met the user's needs with good utilization of the space. The first one is a G-shaped design opened to the dining and salon space. The second one is a U-shaped design also open to the dining and salon space. 


\subsubsection{The First Suggestion: G-shaped Kitchen}

As shown in Figure 27, a G-shaped kitchen type has been suggested with the same dimensions as the existing design. The upper cabinets have been increased, moved up a little bit, and connected to the roof, with being higher than existing ones. Upper cabinets are designed, with adding upper cabinets on the fridge wall. In this suggestion, the spaces have been used and exploited in a way that suits the user's requests and needs. In Figure 27 , the plan of the G-shaped kitchen and the elevation has been clarified with dimensions by using the AutoCAD program.
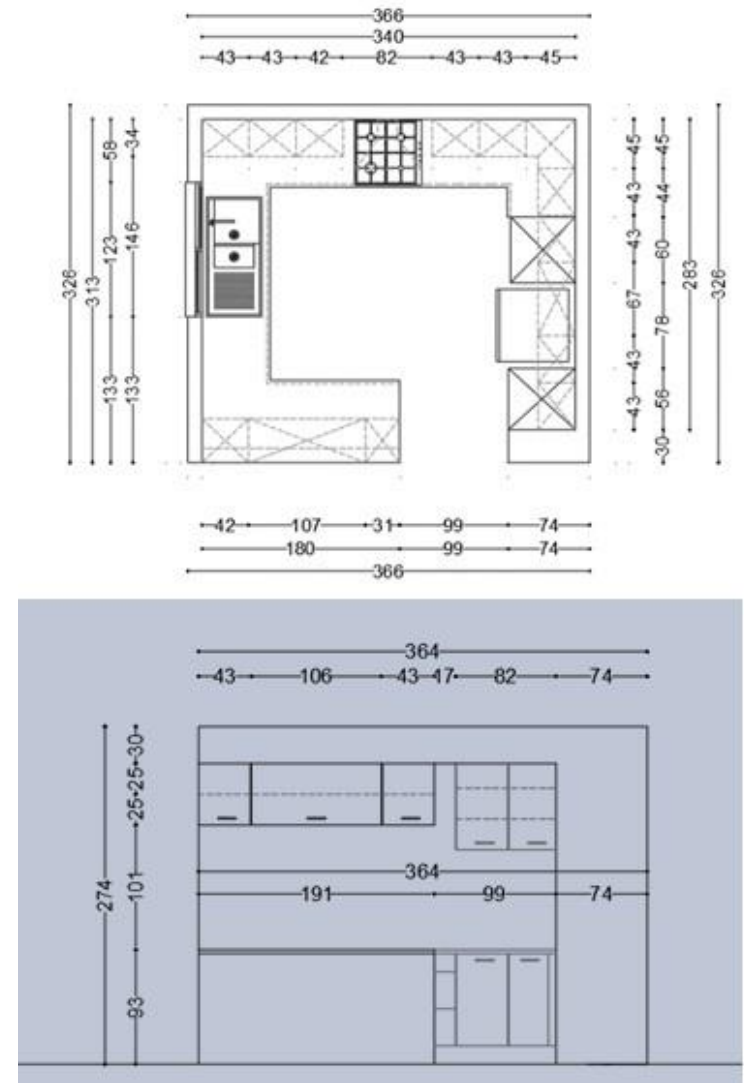

Figure 27: Plan of the suggested G-shaped design with one elevation, (By author, 2020).

\subsubsection{The Second Suggestion: U-shaped Kitchen}

As shown in Figure 28, a U-shaped kitchen type has been suggested with the same dimensions as the existing design. The upper cabinets here have been also increased, moved up a little bit, and connected to the roof, with being higher than existing ones.

Upper cabinets are designed between the kitchen area and the dining area, with adding upper cabinets on the fridge wall. In this suggestion also the spaces have been used and exploited in a way that suits the users' requests and needs, with a different way and type than the first suggestion. In Figure 28, the plan of the U-shaped kitchen and the elevation have been clarified with dimensions by using the AutoCAD program. 

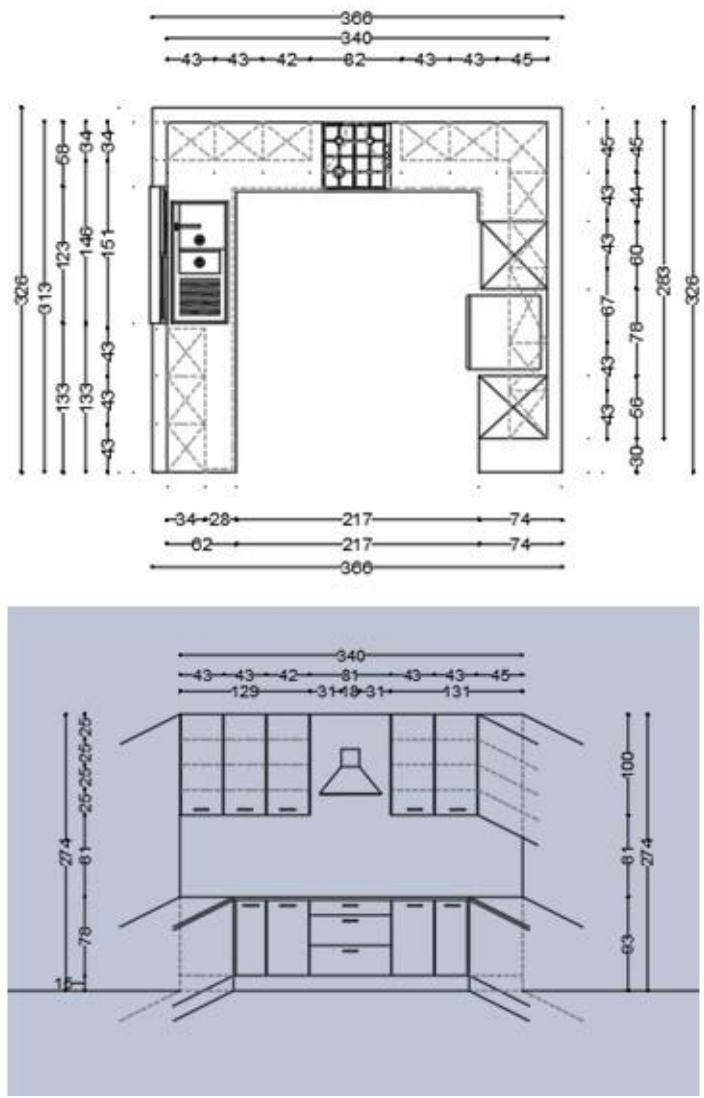

Figure 28: Plan of the suggested U-shaped design with one elevation, (By author, 2020).

\section{Conclusion and Recommendation}

\subsection{Summary of Findings}

This study summarizes, that the kitchen is an essential space, the success of its design depends on the ability of the designer to meet the needs of the user and the knowledge of how to provide the functional and aesthetic features together in one design. Here are the most important points that were found and concluded during this study:

- Understanding the user's needs considered the most important step to can create a successful design.

- The giving of some thought about how users use the current kitchen will help designers plan a new useful one.

- The designer must strive to fulfill the user's need by using the spaces fully and correctly to try to meet all requirements while providing comfortable movement.

- The development of kitchens design over time and the increase in their area and the multiplicity of their types as a result of the designers 'interest in the user's needs and studying the evolution of the users' thinking and increasing their requirements according to the evolution of time. 


\subsection{Conclusion}

The design of any type of architectural space becomes more important and the possibility of its use increases as the needs and requirements of the user meet. Therefore, the user's needs must be met to obtain a correct and successful result. The process of analyzing user needs is the most important step in designing and developing spaces, as setting their goals helps to define the design priorities in the space to reach a result that achieves user comfort. So delving into the user's personality, studying his past experiences, studying the different types of users who will use the product or design, and imagining the characters will help the designer understand the user's needs, experiences, behaviors, and goals in order to seek their fulfillment. The same applies to the design of the kitchen space, the conceptual design of kitchens should start with a clear understanding of the cultural history of the space, as the specific needs of the user, as detailed information about the users enables designers to create more complete and successful spaces. The most important point needed is knowing the kitchen's area and dimensions, as knowing the dimensions helps to determine the kitchen type that corresponds to space to saving a comfortable workspace for the user; where the user's needs are the most important thing in spaces' design. Through a case study of an existing kitchen located in Northern Cyprus, two designs have been suggested which provided aesthetic and functional features at the same time, therefore concludes that the development of the user's thinking or the user changing, may lead to developing the existing design due to different needs and points of view, such as adding new equipment, canceling some of the existing parts, changing the design type or changing the materials used.

\section{References}

Apartment Therapy. (2017). How a Decade of Domesticity Changed Our Nation's Kitchens? Retrieved December 19, 2020 from https://www.apartmenttherapy.com/brief-history-of-1950s-1960s-kitchens-247463

Baden-Powell, C. (2006). Architect's pocket book of kitchen design. Routledge.

Bech-Danielsen, C. (2012). The kitchen: An architectural mirror of everyday life and societal development. Journal of Civil Engineering and Architecture, 6(4), 457-469.

Build. (2020). Single wall kitchens. Retrieved November 20, 2020 from https://build.com.au/single-wall kitchens\#: : :text $=$ Also $\% 20$ known $\% 20 \mathrm{as} \% 20 \mathrm{a} \% 20$ 'single,entirely $\% 20 \mathrm{along} \% 20 \mathrm{a} \% 20$ single $\% 20 \mathrm{wa}$ 11.\&text $=\mathrm{A} \% 20$ single $\% 20$ wall $\% 20$ kitchen $\% 20$ layout,arm's $\% 20$ reach $\% 20$ at $\% 20$ most $\% 20$ times.

Freeman, J. (2004). The making of the modern kitchen: A cultural history. New York: Berg.

Grundig. (2019). Effective kitchen design is the process of combining layout, surfaces, appliances and design details to form a cooking space that's easy to use and fun to cook and socialize in. Retrieved November 20, 2020 from https://www.grundig.com/ktchnmag/blog/what-is-kitchendesign/\#: :text=Effective $\% 20$ kitchen $\% 20$ design $\% 20$ is $\% 20$ the,endless $\% 20$ stream $\% 20$ of $\% 20$ expe $\mathrm{rt} \% 20$ advice

Grundig. (2019). Top tips to get the kitchen layout you need. Retrieved November 20, 2020 from https:/ /www.grundig.com/ktchnmag/blog/the-complete-guide-to-kitchen-layouts/

HGTV. (2020). Kitchen Island Plans. Retrieved November 20, 2020 from https://www.hgtv.com/design/rooms/kitchens/kitchen-island-plans

HGTV. (2020). Modern Kitchen Design. Retrieved November 20, 2020 from https://www.hgtv.com/design/rooms/kitchens/modern-kitchen-design

Home Designing. (2020). 50 Unique U-Shaped Kitchens and Tips You Can Use from Them. Retrieved November 20, 2020 from http://www.home-designing.com/u-shaped-kitchen-design-ideas-inspiration-tipsphotos\#: : :text $=$ The $\% 20 \mathrm{u} \% 2$ Dshaped $\% 20$ layout $\% 20$ places,width $\% 20$ of $\% 20$ the $\% 20$ room $\% 20$ allows. 
House Beautiful. (2016). 100 Years of the American Kitchen. Retrieved December 27, 2020 from https://www.housebeautiful.com/room-decorating/kitchens/g3943/100-years-kitchen/

Kaboodle. (2020). Advantages of L-shaped kitchens. Retrieved November 20, 2020 from https://www.kaboodle.com.au/design-blog/advantages-of-l-shaped-

kitchens\#: :text=A\%20common $\% 20$ kitchen $\% 20$ layout $\% 20$ in,is $\% 20$ the $\% 20 \mathrm{~L} \% 2$ Dshaped $\% 20$ kit chen.\&text $=$ One $\% 20$ of $\% 20$ the $\% 20$ most $\% 20$ efficient,open $\% 20$ area $\% 20$ in $\% 20$ the $\% 20$ centre.

Kaster, G. L. (1996). The American Kitchen, 1700 to the Present: From Hearth to Highrise.

Medialize.it. (2020). Closed Space Open Place. Retrieved November 24, 2020 from http://www.medialize.it/closed-space-open-place/

Pellegrino, P., \& Jeanneret, E. P. (2009). Meaning of space and architecture of place. Semiotica, 2009(175), $269-296$.

Pinterest. (2020). G shaped kitchen layout. Retrieved November 20, 2020 from https://www.pinterest.com/pin/839076974299582886/

Pinterest. (2020). 37 L-Shaped Kitchen Designs \& Layouts (Pictures). Retrieved November 20, 2020 from https://www.pinterest.com/pin/566468459374009456/

Plante, E. M. (1995). The American kitchen, 1700 to the present: From hearth to highrise. Facts on File.

Sani, R. M., Ulucay, B., \& Ulucay, P. (2011). The significance of user participation in Architectural design: the case of Nicosia social housing complex. Archnet-ijar, 5(3).

Science in the classroom. (2020). Can eco-leader-ship save the planet? Retrieved November 20, 2020 from https://www.scienceintheclassroom.org/research-papers/can-eco-leadership-save-planet

Slide Share. (2017). Fue theory 4 lecture 5 - the formulation and analysis of architectural design program and brief. Retrieved November 20, 2020 from https://www.slideshare.net/ymahgoub/fuetheory-4-lecture-5-the-formulation-and-analysis-of-architectural-design-program-and-brief

The Free Dictionary. (2020). kitchen island. Retrieved November 20, 2020 from https://www.thefreedictionary.com/kitchen+island

The Spruce. (2020). 1960s Kitchens: From Jet-Age to Funkadelic. Retrieved December 23, 2020 from https://www.thespruce.com/1960s-kitchens-from-jet-age-to-funkadelic-1821187

The Spruce. (2019). What Is a Galley Kitchen? Retrieved November 20, 2020 from https://www.thespruce.com/make-galley-kitchen-work-for-you-1822121\#: :text=A\%20galley $\% 20$ kitchen $\% 20$ is $\% 20$ a,cabinetry $\% 20$ and $\% 20$ other $\% 20$ functional $\% 20$ items.

Thoring, K., Mueller, R. M., Desmet, P., \& Badke-Schaub, P. (2018). Design principles for creative spaces. In DS 92: Proceedings of the Design 2018 15th International Design Conference (pp. 1969-1980)

Wilson, T. D. (2006). On user studies and informa-tion needs. Journal of documentation, 62(6), 658-670.

Wonderful Kitchens. (2015). Modern Kitchen Design. Retrieved November 20, 2020 from https://wonderfulkitchens.com.au/kitchen-design/characteristics-of-a-modern-kitchen-design/

Wren Kitchens. (2020). How to design a peninsula-style kitchen? Retrieved November 20, 2020 from https://www.wrenkitchens.com/kitchen-design/layout-ideas/how-to-design-a-peninsula-stylekitchen\#: :text $=$ What $\% 20$ is $\% 20 \mathrm{a} \% 20$ peninsula $\% 20$ kitchen,is $\% 20$ attached $\% 20$ to $\% 20$ the $\% 20$ wall

Your Own Architect. (2020). Form and space in archiecture. Retrieved November 20, 2020 https://www.yourownarchitect.com/form-and-space-in-architecture/ 